\title{
The evaluation methods of low-carbon contribution based on the life cycle of low-carbon electricity technologies
}

\author{
Wei Lu ${ }^{1, a}$, Qinggui Chen ${ }^{1, b}$, Zhuhan Long ${ }^{1, c}$ and Ming Zeng ${ }^{1, d}$ \\ ${ }^{1}$ School of Economics and management, North China Electric Power University, Beijing 102206, \\ China;

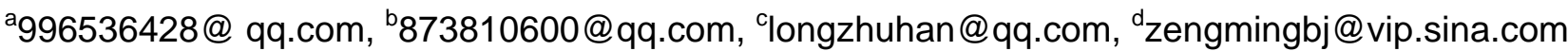

Keywords: Low-carbon electricity technologies, Low-carbon contribution.

\begin{abstract}
In response to the global climate warming and achieving economic and society sustainable development, low-carbon economy is indispensable. Electric power industry is huge carbon dioxide emitter in China, so there is a difficult task in the energy conservation and emissions reduction. The development of low-carbon electricity technologies has important practical significance and strategic significance for the power industry to achieve energy conservation and emissions reduction. This paper studies low-carbon electricity technologies of electric power generation side and electricity using side in our country, analyzes low-carbon electricity technologies based on the life cycle theory, and then establishes low-carbon contribution to evaluate the contribution degree of low-carbon power technologies in power industry for energy conservation and emissions reduction, thus it provides a positive reference to low-carbon development in our country.
\end{abstract}

\section{Introduction}

Global warming is one of the major challenges currently faced by mankind and it has quickly become the focus that governments and the public continuously pay attention to. The United Nations and governments around the world have taken action, set goals that $\mathrm{CO} 2$ emissions reduction by means of legislation or government planning, improve the sustainability of economic development by adjusting the economic structure and improving energy efficiency and other ways, and vigorously explore new ways to provide technologies reserve for $\mathrm{CO} 2$ emissions reduction ${ }^{[1-5]}$. Greenhouse gases such as carbon dioxide, methane, hydrogen fluoride carbide are the main cause of global warming ${ }^{[6]}$. The effect of carbon dioxide to climate warming is as high as $77 \%$. China is huge carbon dioxide emitter around the world, and electric power industry is huge carbon dioxide emitter in China. Therefore, in response to the global climate warming, that the power industry in our country actively promotes low-carbon electricity technologies is necessary ${ }^{[7-9]}$.

The low-carbon electricity technologies of electric power industry in our country throughout power generation and power consumption in the whole power system include clean-coal low-carbon power generation technologies, conventional low-carbon power generation technologies and new low-carbon power generation technologies. The low-carbon electricity technologies in electricity using side mainly includes: the demand side management technologies in power consumption, intelligent power technologies and electric vehicle technologies ${ }^{[10-13]}$. The contribution degree of low-carbon electricity technologies for energy conservation and emissions reduction in power generation side and the electricity using side is different. In order to achieve energy conservation and emissions reduction in China and have the largest carbon emissions reduction effect with limited conditions, actively study the low-carbon electricity technologies is of great significance. The life cycle focuses on long-term benefits and comprehensively investigates low-carbon electricity technologies, so the life cycle theory is an effective method to evaluate energy-saving benefits of low-carbon electricity technologies. Therefore, based on the theory of life cycle, this paper puts forward the concept of low-carbon contribution to evaluate low-carbon electricity technologies and emissions reduction effect, and then, provides some guide to low-carbon development in our country. 


\section{Low-carbon contribution and its evaluation method}

\subsection{Definition of low-carbon contribution}

n economics, the contribution is a commonly used as an indicator to analyze the economic benefits, also used to analyze the effect degree of various factors in economic growth. In accounting cost calculation, contribution refers to the difference between the commodity price and variable cost. This paper focuses on low-carbon contribution of low-carbon electricity technologies, and puts forward the concept of low-carbon contribution on the basis of contribution theory in economics and accounting.

Low-carbon contribution is an evaluation index to measure the carbon reduction benefits of some low-carbon electricity technologies. Referring the methods for calculating the contribution in accounting, this paper defines low-carbon contribution of low-carbon electricity technologies as follows: low-carbon contribution is carbon reduction benefits measured by a set of complete system for some low-carbon electricity technologies comparing to conventional thermal power technologies, as following:

$$
L C C=C E R_{C}-C E R_{L}
$$

$L C C$ is for low carbon contribution, $C E R_{C}$ is for carbon reduction coefficient of conventional thermal power technologies, $C E R_{L}$ is for carbon reduction coefficient of low-carbon electricity technologies

\subsection{Low-carbon contribution evaluation methods based on the life cycle}

Life cycle analysis (LCA) studies energy requirements, raw materials using and waste emissions to the environment in detail in life cycle, including the raw materials recycling, manufacturing/processing, distribution and use/reuse/waste disposal after maintenance. On this basis, the comparison in the final plan includes reduces energy demand, raw materials use, waste disposal, regeneration and resource conservation, etc. From the perspective of life cycle, this paper calculates the contribution of low-carbon based on the carbon reduction coefficient of all kinds of low-carbon electricity technologies.

\section{Analyzing low-carbon contribution of low-carbon electricity technologies}

\subsection{Clean-coal low-carbon electricity technologies}

In power generation side low-carbon electricity technologies, the integrated gasification combined cycle power generation technologies is relatively mature and commercial operation instances are rich, so this paper introduces clean-coal low-carbon electricity technologies through integrated gasification combined cycle power generation technologies as a representative.

(1) The evaluation principle

Low-carbon contribution evaluation principle of IGCC power generation systems is mainly based on the life cycle analysis method and the working process of the coal gasification combined cycle power generation systems. IGCC power generation technologies is composed of two parts, namely, coal gasification and essence, and gas - steam combined cycle power generation.

(2) Evaluation procedures

Based on life cycle analysis method, the specific evaluation procedures of IGCC power system low-carbon contribution are: first, calculate IGCC power generation efficiency through the system coal consumption and generation, namely the IGCC system efficiency is equal to the coal gasification cold gas efficiency multiplied by gas-steam combined cycle power generation efficiency; second, calculate energy consumption of IGCC evaluation system. The part of coal gasification steam consumption is supplied by steam which is discharged from waste heat boiler, therefore, calculating the system energy consumption just needs to consider the influence of house-service consumption; third, based on the calculation results from above two steps, analyze CO2 emissions per unit of IGCC system.

(3) The evaluation model

a. Model parameters 
The input parameter of Coal gasification technologies evaluation model is the raw material coal, and output parameters are crude gases, including carbon monoxide, hydrogen gas, CO2, methane, hydrogen sulfide, nitrogen and water.

b. Evaluation model

At present, most international IGCC plants are using Shell dry pulverized coal gasification technologies. This report mainly adopts the Shell dry pulverized coal gasification evaluation model established by coal industry clean-coal technology research center.

The calculation model of coal gasification efficiency is as following:

$\eta_{5}=\frac{Q_{\mathrm{H}_{2}}+Q_{c o}+Q_{\mathrm{N}_{2}}+Q_{\mathrm{CO}_{2}}}{Q_{\text {rawcoal }}}$

IGCC power generation efficiency:

$\eta_{1}=\eta_{5} \times \eta_{\mathrm{CC}}$

Where, $\eta_{1}$ is supercritical power generation efficiency; $\eta_{5}$ is the efficiency of coal gasification chill gas; $\eta_{c c}$ is the efficiency of gas and steam combined cycle power generation.

Supercritical power generation efficiency:

$\eta_{4}=\eta_{1} \times(1-\alpha)$

Where, $\eta_{4}$ is the efficiency of power supply; $a$ is auxiliary power rate.

$\mathrm{CO}_{2}$ emissions of supercritical per unit power:

$$
\begin{aligned}
W_{\mathrm{co}_{2}} & =\frac{M_{c o_{2}}}{\frac{M \times Q_{n e t, a r} \times \eta_{4}}{3600}} \times 1000 \\
M_{\mathrm{co}_{2}} & =\frac{M \times C_{a r} \times \beta \times 44}{12}
\end{aligned}
$$

Where, $W_{\mathrm{co}_{2}}$ is $\mathrm{CO}_{2}$ emissions per unit power; $M_{\mathrm{co}_{2}}$ is $\mathrm{CO} 2$ generation; $M$ is coal consumption; $C_{a r}$ is carbon content receiving; $\beta$ is carbon conversion rate.

\subsection{Solar photovoltaic power technologies}

(1) The evaluation methods

Appling LCA method to evaluate low-carbon contribution of solar photovoltaic power generation technologies needs to clear that which parts will discharge pollutants during the life cycle. Photovoltaic industry chain is a span wide energy intensive, technologies intensive and capital intensive industry chain. Raw materials and production equipment suppliers are located in the industrial chain upstream. The producers of solar cell and packaging part are the midstream. Developers of various application products and parts (including battery and inverter, etc.) and broad application market are downstream. Photovoltaic power generation system doesn't produce $\mathrm{CO}_{2}$ in operation stage, but in the production process of raw materials and equipment that it needs will emit $\mathrm{CO}_{2}$.

(2) The evaluation procedures

We can know from solar photovoltaic emissions list that the production process of raw materials and equipment required by photovoltaic power generation system is the main source of carbon emissions in the life cycle. From the perspective of life cycle, the low-carbon contribution evaluation of solar photovoltaic power generation technologies includes three steps:

a. Evaluate energy consumption of photovoltaic power generation system in the life cycle, and we can know energy consumption per kilowatt.

b. Measure the total generation of photovoltaic power generation system, and determine the total generation according to the specific project.

c. Calculate $\mathrm{CO}_{2}$ emissions coefficient of photovoltaic power generation system. The $\mathrm{CO}_{2}$ emissions coefficient expression of photovoltaic power generation system is shown below: 


$$
C F=\frac{E C \times \delta \times \theta}{T G}
$$

Where, $C F$ is $\mathrm{CO}_{2}$ emissions coefficient; $E C$ is energy consumption of photovoltaic power generation system in the life cycle (measure with equivalent $\mathrm{kWh}$ ); $\delta$ is the conversion coefficient of standard coal in power consumption, desirable 1.229tce/ten thousand $\mathrm{kWh} ; \theta$ is $\mathrm{CO}_{2}$ emissions factor of standard coal, desirable $3 \mathrm{tCO}_{2} / \mathrm{tce}$; $T G$ is the total generation of photovoltaic power generation system in the life cycle $(\mathrm{kWh})$.

\subsection{Electricity using side}

Electricity saving potential of power demand side refers to the amount of electricity power saved by end users, including saved power and saved electricity. Because its potential is waiting for discovery, it is commonly called as electricity saving potential.

The analysis of electricity saving potential mainly includes four steps: first, estimate technical potential; second, estimate economic potential; third, estimate market potential; forth, estimate the avoided power and avoided peak load capacity of DSM power saving system.

\section{(1) The evaluation methods of technical potential}

Technical potential refers to the technically feasible power saving resource during the planning period, which is the saved resource as long as the efficiency of the used technology is higher than the current ones.

Divide all kinds of electricity terminal technologies during the planning period into three groups. The first group is the equipment which is being using in benchmark year of the planning period; the second group is the new equipment during the planning period (including the retired old equipment during the planning period); the third group is the high efficiency equipment that will replace all energy consuming equipment in target year of the planning period.

Assuming that the efficiency of the first group equipment is $a_{1}$, the efficiency of the second group is $a_{2}$, the efficiency of the third group is $a_{3}$, and then the technical potential of such equipment (TP) is:

$$
T P=\left(a_{3}-a_{1}\right) A_{1}+\left(a_{3}-a_{2}\right)\left(A_{3}-A_{1}\right)
$$

Where, TP is the technical potential of DSM measures; $A_{1}$ is annual energy consumption of this equipment in benchmark year; $A_{3}$ is annual energy consumption of this equipment in target year; $a_{1}$ is the efficiency of this equipment in group $i$.

\section{(2) The evaluation methods of economic potential}

Economic potential refers to the power saving resource which is technically feasible and economically rational. It is the cost-effective power saving resource that is determined through a cost benefits analysis on the basis of the technological potential. Digging these resources can obtain not only technical efficiency, but also economic efficiency, and then obtain energy saving benefits.

DSM measures may not own cost benefits. If DSM owns cost benefits, its economic potential is equal to its technologies potential, otherwise the economic potential is 0 . Economic potential is related to investment recovery period and return that consumers expect. When DSM measures have cost benefits, namely the benefit-cost ratio (BCR) of project is greater than or equal to 1 , EP = TP; When DSM measures have no cost benefits, namely the benefit-cost ratio of project (BCR) is less than $1, \mathrm{EP}=0$.

Among them,

$$
B C R=\frac{\sum_{i=0}^{n} B_{i}(1+p)^{-i}}{\sum_{i=0}^{n} C_{i}(1+p)^{-i}}
$$

Where, EP is the economic potential of DSM measures; $B C R$ is the benefit-cost ratio of DSM project; $B_{i}$ is the benefits of the project in the year $\mathrm{i} ; C_{i}$ is the cost of the project in the year $i ; p$ is 
the return on investment or social discount rate of the project; $n$ is the life cycle or investment recovery period that consumers expect of the project.

\section{(3) The evaluation methods of market potential}

Market potential refers to the power saving resources expected to achieve after entering the market through cost-effective methods of energy saving. It should be based on the reliable user participation rate, and then promote the resource potential explored by the market operation strategies.

In the process of implementing DSM, the information publicity may be not enough, the market penetration of new technologies may be not high, or market service may be imperfect and other reasons. And then, cost-effective DSM measures may not be comprehensively applied. This report uses user participation rate to describe the obstacles in the implementation period of the DSM measures. User participation rate is the users who take DSM measures account for all users involved in the planning period. The calculation formula of market potential is:

$M P=\omega \times E P$

Where, $M P$ is the market potential of DSM measures; $\omega$ is the user participation rate.

The market potential of DSM measures is the available power saving potential of promoting to implement electricity saving technologies of demand side management, and it is the potential which can be actually obtained.

\section{(4) Avoided power and avoided peak load capacity of the system}

The potential analysis of power demand side management is to reasonably analyze and forecast the power saving potential from power demand side management promotion and implementation. Power saving resources include power saving and electricity saving. In the process of analyzing the potential and benefits of DSM measures, the main analysis indicators should be the generation and the installed generating capacity avoided by the supply side. However, the generation and the installed generating capacity avoided by the supply side don't mean the power and electricity saved by end users. Therefore, in the analysis process, it needs to convert some corresponding indicators.

a. Avoided power of the system

According to the requirement of the calculation for the project cost-benefits, it usually needs to calculate the avoided power of the system. Avoided power refers to the generation that the supply side avoids due to the end users saving electricity. The calculation formula is:

$$
\Delta E_{c}=\frac{\Delta E_{o}}{(1-l)(1-\alpha)(1-\beta)}
$$

Where, $\Delta E_{c}$ is avoided power of the system; $\Delta E_{o}$ is the saving power of terminal measures; $l$ is the loss coefficient of terminal distribution; $\alpha$ is the loss coefficient of grid distribution; $\beta$ is auxiliary power rate of power plant.

b. Avoided peak load capacity

The avoided peak load capacity in the IRP and DSM is usually referred to as avoided capacity. It is the avoided generating capacity in grid peak load period due to electricity saving, and that is the avoided installed capacity in the grid peak load period, the calculation formula is:

$$
\Delta P_{c}=\Delta P_{b} \times \frac{1}{(1-l)(1-\alpha)(1-\beta)(1-\gamma)}
$$

Where, $\Delta P_{c}$ is the avoided capacity; $\Delta P_{b}$ is the saving power of end users; $\gamma$ is the coefficient of the system spare capacity.

\section{Summary}

Based on the theory of life cycle, this paper analyzes the low-carbon efficiency of low-carbon electricity technologies in power generation side and electricity using side of our country's electric power industry, and puts forward low-carbon contribution to evaluate carbon reduction benefits of low-carbon electricity technologies. Through analyzing and evaluating low-carbon contribution of 
different low-carbon electricity technologies based on life cycle, we get different low-carbon electricity technologies evaluation methods of power generation side and electricity using side.

\section{Reference}

[1]Stern N. The economics of climate change: The Stern Review[M]. Cambridge University Press, 2007

[2]Grubb M, Butler L, Twomey P. Diversity and security in UK electricity generation: the influence of low-carbon objectives[J]. Energy Policy, 2006, 34(18): 4050-4062

[3]Foxon T J . Inducing innovation for a low-carbon future : Drivers, [4]Barriers and Policies[M]. London: Carbon Trust, 2003

[5]Svante Mandell. Optimal mix of tes taxes and cap-and-trade[J]. Journal of Environmental Economics and Management, 2007, 12: 1-10

[6]Zhang Kunmin, Pan Jiahua, Cui Dapeng. Introduction to Low Carbon Economy[M]. Beijing: China Environmental Science Press, 2008

[7]Wei Yiming, Liu Lancui, Fan Ying, China Energy Report (2008): $\mathrm{CO}_{2}$ Emissions Research[M]. Beijing: Science Press, 2008

[8]He Jiankun, Zhang Xiliang, Li Zheng. CO2 emissions scenarios on several issues in China's energy development[J]. Science Technology Review, 2008, 2: 90-92

[9]Wu Ruosi, Su Wenbin, Zheng Song. The Challenge of Global Climate Change, Carbon Capture and Sequestration[M]. Beijing: China Water Power Press, 2008

[10]Boemare C, Quirion P, Sorrell S. The evolution of emission trading in the EU: Tensions between national trading schemes and the proposed EU directive[J]. Climate Policy, 3(S2): S105-S124

[11]James Murphy, John Stranlund. A laboratory investigation of compliance behavior under tradable emissions rights: Implications for targeted enforcement[J]. Journal of Environmental Economics and Management, 2007, 53: 196-212

[12]Liu Lancui. China's carbon dioxide emissions reduction policy modeling and empirical analysis of the problem[D]. University of Science and Technology of China, 2006

[13]Liu Lancui, Wu Gang. The status of China's CDM projects[J]. Energy of China,2007,29(3) 